\title{
STUDY OF URINARY PROTEIN AND LEUCOCYTES IN NORMOTENSIVE AND HYPERTENSIVE CHILDREN AND ADULTS
}

\author{
Tirthankar Guha Thakurta1, Pulak Panda²
}

${ }_{1}^{1}$ Postgraduate Trainee, Department of Physiology, KPC Medical College and Hospital, Jadavpur, Kolkata. 2Professor and HOD, Department of Physiology, KPC Medical College and Hospital, Jadavpur, Kolkata.

\section{ABSTRACT}

\section{BACKGROUND}

Proteinuria is a known indicator of early stages of hypertensive nephropathy in adults. However, the role of proteinuria in diagnosis of hypertensive target organ damage in hypertensive children is not well documented. The purpose of this study is to investigate the prevalence of proteinuria and pyuria in children and adults with hypertension, and compare it with the prevalence in normotensive population in both children and adults.

\section{MATERIALS AND METHODS}

Urine from 200 hypertensive and 200 normotensive individuals was collected. Out of 200 individuals in each group, 100 were below 18 years of age, and 100 were above 18 years of age. The urine samples were tested by strip test with multiple parameters for protein and leucocytes and the latter was confirmed by microscopic examination.

\section{RESULTS}

In our study, $17 \%$ of the hypertensive subjects in the younger age group ( $<18$ years of age) were diagnosed with proteinuria in contrast to only $2 \%$ of the normotensive subjects in the same age group. Sixty-two percent of the hypertensive adults were diagnosed to have proteinuria in comparison with only $4 \%$ of normotensive adults who had a positive test for protein in their urine.

\section{CONCLUSION}

Chronic pyelonephritis is regarded as an important secondary cause of paediatric hypertension. But the prevalence of pyuria was not found to be remarkably higher in hypertensive children compared to the normotensive children. Our findings suggest that paediatric hypertension can also be associated with proteinuria which can be used as a marker for target organ injury in children.

\section{KEYWORDS}

Urinary Protein and Leucocytes, Hypertensive Children, Hypertensive Adults.

HOW TO CITE THIS ARTICLE: Thakurta TG, Panda P. Study of urinary protein and leucocytes in normotensive and hypertensive children and adults. J. Evolution Med. Dent. Sci. 2017;6(25):2069-2072, DOI: 10.14260/Jemds/2017/450

\section{BACKGROUND \\ An important indicator of hypertensive vascular disease in adults is the target organ damage (TOD) caused by elevated blood pressure.[1] Target organ damages include changes in heart (left ventricular hypertrophy), blood vessels (increased carotid artery intimal thickness), eyes (hypertensive retinopathy), kidneys (hypertensive nephropathy) and other organs.[1-6] However, studies by different workers have suggested that TODs are less prominent in hypertensive children.[2,7] \\ The definition of hypertension in adults is based on the relationship between blood pressure levels and incidence of adverse cardiovascular events like stroke, myocardial infarction, hypertensive nephropathy and hypertensive retinopathy.[2] Similar data to define paediatric hypertension that are based on target organ damage are not available.[2] Children often do not develop the target organ damages to such an extent to warrant clinical manifestations.[2,7]}

Financial or Other, Competing Interest: None.

Submission 12-02-2017, Peer Review 15-03-2017,

Acceptance 21-03-2017, Published 27-03-2017.

Corresponding Author:

Dr. Tirthankar Guha Thakurta,

4 A East Road, Jadavpur,

Kolkata-700032.

E-mail: tirthankar.guhathakurta@gmail.com

DOI: $10.14260 /$ jemds $/ 2017 / 450$

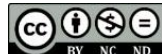

Chronic hypertension leads to hypertensive nephropathy, a common cause of kidney disease. ${ }^{[8]}$ Proteinuria is a known indicator of early stages of hypertensive nephropathy.[9] Excretion of albumin in the range of $30-300 \mathrm{mg}$ in 24 hours or an Albumin: Creatinine Ratio (ACR) of 30 to 300 $\mu \mathrm{g}$ albumin $/ \mathrm{mg}$ creatinine is an indicator of microalbuminuria.[1] Aggressive blood pressure control to $130 / 80 \mathrm{mmHg}$ or lower slows the progression of all forms of chronic kidney disease, especially when proteinuria is present.[10,11]

Microalbuminuria predicts progressive deterioration of renal function and an increased risk of cardiovascular (CV) events/death in adults.[2] Recently, Assadi demonstrated that even in children with essential hypertension, the treatment of microalbuminuria by renoprotective therapy (Angiotensin converting enzyme inhibitors or angiotensin-receptor blockers) was associated with regression of left ventricular hypertrophy.[12]

The purpose of this study is to investigate the prevalence of proteinuria and pyuria in children and adults with hypertension, and compare it with the prevalence in normotensive population in both children and adults.

\section{MATERIALS AND METHODS}

The subjects were chosen from school-going children of different schools in Kolkata (for $<18$ years of age). Subjects of more than 18 years of age were selected from the students 
and staff of our Institution. Informed consent of the individuals was taken. The study was approved by the Institutional Ethical Committee of KPC Medical College and Hospital, Jadavpur, Kolkata.

\section{Inclusion Criteria}

All consenting individuals between 10 years to 60 years of age.

\section{Exclusion Criteria}

- Presence of known primary renal disease.

- Presence of known non-hypertensive causes of nephropathy (e.g. Diabetes mellitus).

- Individuals taking drugs that can alter urinary protein output (e.g. ACE inhibitors).

- Individuals with clinical features of active urinary tract infection.

Stratified random sampling method was used for the selection of study subjects. 1000 respondents who were part of the study were divided into two strata. The first stratum included individuals $<18$ years of age and the second stratum included individuals $>18$ years of age. In each stratum 100 hypertensive and 100 normotensive subjects were selected by random sampling. Total number of subjects was 400 .

\section{The Following Formula was used to calculate the Sample} Size-

$\mathrm{n}=\mathrm{Z}^{2} \mathrm{pq} / \mathrm{e}^{2}$,

where, $\mathrm{n}=$ required sample size.

$\mathrm{Z}=$ normal standard deviation which is equal to $1.96 \%$ at $5 \%$ significance level.

$\mathrm{p}=$ prevalence of proteinuria among hypertensive subjects in India, which is $37.5 \% .{ }^{[13]}$

$q=(100-p)$, i.e. $(100-37.5) \%=62.5 \%$.

The allowable error (e) is $5 \%$.

Therefore, the minimum sample size $(\mathrm{n})=\mathrm{Z}^{2} \mathrm{pq} / \mathrm{e}^{2}$

$=(1.96)^{2} \times 37.5 \times 62.5 /(5)^{2}$

$=360.15$.

$=360$.

Considering $10 \%$ non-response rate, the sample size (n) would be- $n=[360+(10 \%$ of 360$)]=360+36=396$.

We studied 400 subjects after stratified random sampling.

Urine from 200 hypertensive and 200 normotensive individuals was collected. Out of 200 individuals in each group, 100 were below 18 years of age, and 100 were above 18 years of age. The urine samples were tested for presence of protein and leucocytes or pus cells.

A strip test with multiple parameters (Multistix) was used for urinalysis. A standard urine test strip comprises of 10 different chemical pads or reagents which react (Change colour) when immersed in, and then removed from, a urine sample. The test can often be read in as little as 60 to 120 seconds after dipping.[14]

Multistix contains tetrabromophenol blue indicator for protein detection with a buffer to maintain the $\mathrm{pH}$ at a constant level. As the protein concentration increases, the colour of the indicator progresses through various shades of green and finally to blue. The interpretation of the result was done according to the guidelines provided with the kit[14] [Figure 1].
Presence of leucocytes or pus cells was further confirmed by microscopic examination of urine under high power objective (400 x magnification) and reported in units of numbers of cells per high power field (n/HPF).

A sample of well-mixed urine measuring $10 \mathrm{~mL}$ is centrifuged in a centrifuge tube at 3,000 rpm for 10 minutes until a deposit is produced at the bottom of the tube. The supernate is decanted until a volume of $0.5 \mathrm{~mL}$ is left inside the tube. The sediment is dissolved in the residual supernate by tapping the bottom of the tube. A drop of resuspended sediment is placed on a glass slide, secured with coverslip and examined under 40x objective (high power) of microscope. Usually there are about 0 - 5 leucocytes per high power field in a normal sample of urine, with females having slightly higher in numbers due to vaginal contamination.

The urine strip test for white blood cells detects leucocyte esterase, which is present in azurophilic granules of leucocytes. The urine strip test reaction for leucocytes is based on the action of leucocyte esterase in catalysing the hydrolysis of an ester of indolecarboxylic acid. The indoxyl that is liberated combines with a diazonium salt in order to produce a violet coloured azole dye.[14,15]

\section{Reactions Catalysed by Leucocyte Esterase[14,15] are-}

i. Indolecarboxylic acid ester $\rightarrow$ Indoxyl + Acid.

ii. Indoxyl + Diazonium salt $\rightarrow$ Violet azole dye.

The esterase reaction needs about 5 minutes to take place. The presence of strong oxidising agents or formaldehyde can cause false positives. False negative results are associated with elevated concentrations of protein (Greater than $500 \mathrm{mg} / \mathrm{dL}$ ), glucose (Greater than $3 \mathrm{~g} / \mathrm{dL}$ ), oxalic acid and ascorbic acid. Urine with a high specific gravity can also cause leucocyte crenation, which can impede the liberation of the esterases.[16]

\section{Statistical Analysis}

The data were analysed using Microsoft Excel 2007. Piecharts and bar-diagrams were constructed representing the distribution of the urinary findings in the two age groups. Accordingly, the prevalence of proteinuria and pyuria in normotensive and hypertensive children and adults were calculated and compared.

\section{RESULTS}

Urine was tested for protein and leucocytes in 200 hypertensive individuals and 200 normotensive individuals (with each group comprising of 100 individuals under 18 years of age, 100 individuals at or above 18 years of age).

The findings are presented in Charts 1 - 4 .

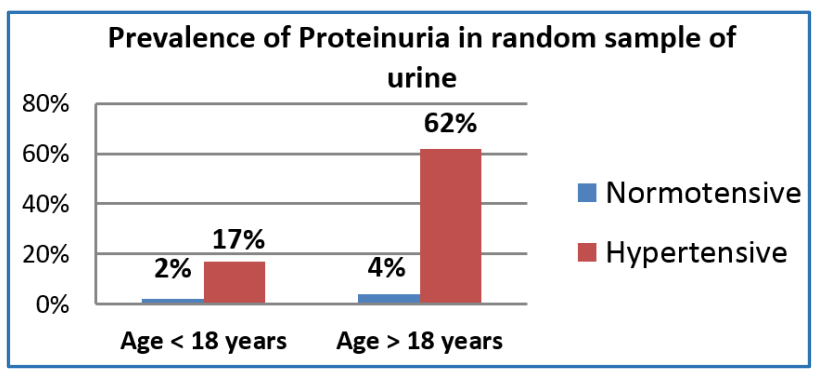

Chart 1. Prevalence of proteinuria revealed by dipstick examination of random sample of urine in hypertensive and normotensive subjects of different age groups 
The prevalence of proteinuria was markedly higher in hypertensives, compared to normotensive subjects in both adults and children.

The severity of proteinuria among hypertensive and normotensive subjects is presented below.

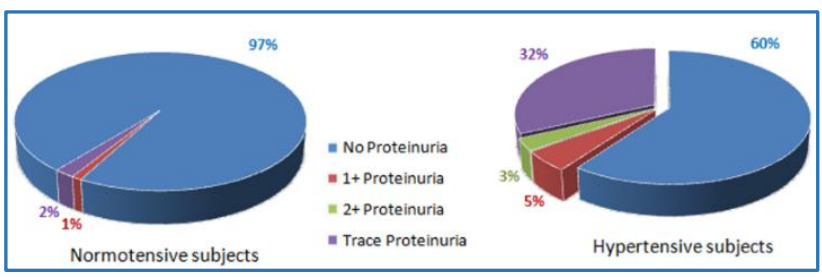

Chart 2. Findings of urine examination for protein in normotensive and hypertensive individuals

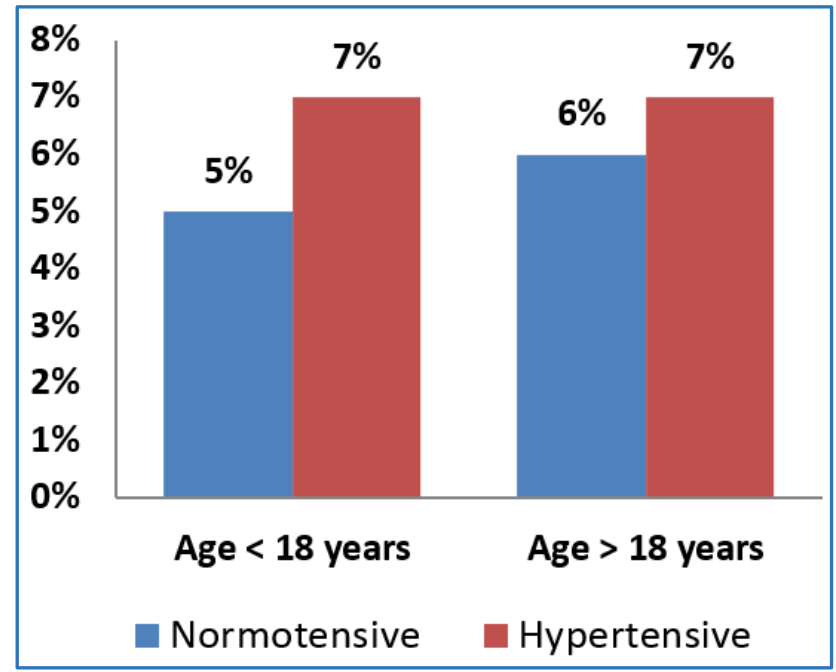

Chart 3. Prevalence of pyuria revealed by dipstick examination of urine in hypertensive and normotensive subjects of different age groups.

\begin{tabular}{|c|c|c|c|c|c|c|c|c|}
\hline \multirow[b]{2}{*}{ LEU } & \multicolumn{8}{|c|}{ TESTS AND READING TIME } \\
\hline & $\begin{array}{l}\text { LEUKOCYTES } \\
2 \text { minutes }\end{array}$ & NEGATIVE & & & TRACE & sumpl & Moosants & $\underline{4065}$ \\
\hline PRO & $\begin{array}{l}\text { PROTEN } \\
60 \text { seconds }\end{array}$ & neative & trace & ayou & 30 & $\stackrel{100}{*}$ & $\stackrel{n}{*}$ & 2000 or ferer \\
\hline
\end{tabular}

Figure 1. Grading of leucocyte count and proteinuria by urine dipstick test (Multistix)

\section{DISCUSSION}

Many authors have implicated chronic pyelonephritis as an important secondary cause of paediatric hypertension.[6] Chronic pyelonephritis is associated with increase in pus cells in urine. In our study; however, the prevalence of pyuria was not found to be remarkably higher in hypertensive children, compared to the normotensive children.

Proteinuria, particularly microalbuminuria, is a known early marker of hypertensive nephropathy in adults.[1] In our study, prevalence of proteinuria (Estimated by dipstick method) was markedly higher in hypertensive individuals, compared to normotensive individuals. An interesting finding was that the prevalence of proteinuria was also higher in hypertensive children, as compared to their age-matched counterparts. This is important, as we often think that hypertension in children may not produce target organ changes.

Previous studies have shown that children with hypertension develop subtle target organ damages like increased carotid artery intimal medial thickness,[17] left ventricular enlargement, structural changes in forearm vessels,[18] narrowing of retinal arterioles,[19] among other changes. Proteinuria; however, is easier to estimate and far less expensive compared to the above parameters. Studies conducted by Assadi[17] has demonstrated that controlling microalbuminuria in children by ACE inhibitors or Angiotensin receptor blockers causes regression of left ventricular hypertrophy. Thus, detection of proteinuria in hypertensive children may have both diagnostic and prognostic implications.

In our study, $17 \%$ of the hypertensive subjects in the younger age group $(<18$ years of age) were diagnosed with proteinuria; in contrast to only $2 \%$ of the normotensive subjects in the same age group who had proteinuria.

The prevalence of proteinuria in the hypertensive adults was even higher. Sixty-two percent of the hypertensive adults were diagnosed to have proteinuria in comparison with only $4 \%$ of normotensive adults who had a positive test for protein in their urine.

The significance of the findings may be an indication that children with raised blood pressure are prone to target organ changes as seen in adults. It may be therefore useful to screen children with proteinuria for hypertension, and hypertensive children may be advised for baseline urinary protein estimation.

\section{CONCLUSION}

Our study indicates that children who suffer from hypertension can also develop proteinuria indicating renal damage. It may be useful to screen hypertensive children for proteinuria and vice versa, to improve monitoring of hypertensive target organ damage and initiate appropriate therapeutic measures. Our findings suggest that paediatric hypertension can also be associated with proteinuria which can be used as a marker for target organ injury in children.

\section{REFERENCES}

[1] Longo DL, Fauci A, Kasper D, et al. eds. Hypertensive vascular disease. Harrison's Principles of internal medicine. 18 ${ }^{\text {th }}$ edn. McGraw-Hill 2012:1463-81.

[2] Falkner B. Hypertension in children and adolescents: epidemiology and natural history. Pediatr Nephrol 2010;25(7):1219-24.

[3] Daniels SR, Loggie JMH, Khoury $P$, et al. Left ventricular geometry and severe left ventricular hypertrophy in children and adolescents with essential hypertension. Circulation 1998;97(19):190711.

[4] Hanevold C, Waller J, Daniels S, et al. The effects of obesity, gender and ethnic group on left ventricular hypertrophy and geometry in hypertensive children: a collaborative study of the International Pediatric Hypertension Association. Pediatrics 2004;113(2):328-33. 
[5] McNiece KL, Gupta-Malhotra M, Samuels J, et al. Left ventricular hypertrophy in hypertensive adolescents: analysis of risk by 2004 National High Blood Pressure Education Program Working Group staging criteria. Hypertension 2007;50(2):392-5.

[6] Brady TM, Fivush B, Flynn JT, et al. Ability of blood pressure to predict left ventricular hypertrophy in children with primary hypertension. J Pediatr 2008;152(1):73-8.

[7] Lande MB. Systemic hypertension. In: Kliegman R, Stanton B, St. Geme J, et al. eds. Nelson textbook of pediatrics. 19th edn. St. Louis: Saunders 2011:1639-47.

[8] Genovese G, Friedman DJ, Ross MD, et al. Association of trypanolytic ApoL1 variants with kidney disease in African Americans. Science 2010;329(5993):841-5.

[9] Bakris GL, Williams M, Dworkin L, et al. Preserving renal function in adults with hypertension and diabetes: a consensus approach. American Journal of Kidney Diseases 2000;36(3):646-61.

[10] James PA, Oparil S, Carter BL, et al. 2014 evidencebased guideline for the management of high blood pressure in adults: report from the panel members appointed to the Eighth Joint National Committee (JNC 8). Jama 2014;311(5):507-20.

[11] Larson EW, Edwards WD. Risk factors for aortic dissection: a necropsy study of 161 cases. American Journal of Cardiology 1984;53(6):849-55.

[12] Berenson GS, Wattigney WA, Tracy RE, et al. Atherosclerosis of the aorta and coronary arteries and cardiovascular risk factors in persons aged 6 to 30 years and studied at necropsy (The Bogalusa Heart Study). Am J Cardiol 1992;70(9):851-8.
[13] Jalal S, Sofi FA, Sidiqqi MA, et al. Prevalence of Microalbuminuria in essential hypertension: a study of patients with mild to moderate hypertension. Indian J Nephrol 2001;11:6-11.

[14] Simerville JA, Maxted WC, Pahira JJ. Urinalysis: a comprehensive review. American Family Physician 2005;71(6):1153-62.

[15] Wise KA, Sagert LA, Grammens GL. Urine leukocyte esterase and nitrite tests as an aid to predict urine culture results. Lab Med 1984;15(3):186-7.

[16] Kusumi RK, Grover PJ, Kunin CM. Rapid detection of pyuria by leukocyte esterase activity. JAMA 1981;245(16):1653-5.

[17] Assadi F. Effect of microalbuminuria lowering on regression of left ventricular hypertrophy in children and adolescents with essential hypertension. Pediatric Cardiology 2007;28(1):27-33.

[18] Raitakari OT, Juonala M, Kahonen M, et al. Cardiovascular risk factors in childhood and carotid artery intima-media thickness in adulthood: the Cardiovascular Risk in Young Finns Study. JAMA 2003;290(17):2277-83.

[19] Lande MB, Kaczorowski JM, Auinger P, et al. Elevated blood pressure and decreased cognitive among schoolage children and adolescents in the United States. J Pediatr 2003;143(6):720-4. 